\title{
BRONCHIAL PROVOCATION TESTS
}

\author{
M.K. BENSON \\ Churchill Hospital, Headington, Oxford OX3 7LJ
}

Certain patients, especially those with asthma, exhibit an increased bronchoconstrictor response to a variety of stimuli. Bronchial provocation tests have developed as a method of assessing this bronchial hyperreactivity. They involve the measurement of lung function tests relating to airway calibre before and after brief exposure to a constrictor stimulus.

Tests using non-specific bronchoconstrictor stimuli such as histamine or cholinergic drugs, will produce a constrictor response in all subjects if given in sufficient dosage. There are, however, large quantitative differences between individuals in the responsiveness to these stimuli. In contrast to these non-specific challenges, reactions to certain allergens or to other stimuli such as toluene di-isocyanate are seen only in subjects who have developed a specific sensitivity. These patients therefore differ qualitatively from normal subjects.

Although the clinical implications of bronchial hyperreactivity have been noted for several centuries, it is only recently that bronchial provocation tests have been used to any significant extent. There is still considerable debate as to the clinical value of challenge testing and their use has led to conflicting views on the underlying pathophysiology. In part these differences can be attributed to variations in technique used for bronchial challenge. Before considering the problems it is helpful to examine the main indications for performing bronchial challenge tests.

(1) As a diagnostic test. The use of non-specific bronchial challenge tests may be of diagnostic value especially in patients who complain of episodic wheeze or dyspnoea but who are clinically and physiologically normal at the time of study. A more contentious issue is whether bronchial provocation tests can be used to differentiate patients with variable airway obstruction (asthma) from those with relatively fixed obstruction (chronic obstructive bronchitis).

(2) To identify specific provoking factors. Inhalation of specific stimuli may help in identifying environmental factors which may be contributing to respiratory difficulty. In the case of di-isocyanates and other occupationally related substances, this can be done either by making measurements of lung function at the place of work or under simulated conditions in the laboratory. In either situation sensitized individuals will show a change in lung function on exposure to relatively low concentrations whereas normal subjects exhibit no reaction to higher concentrations. The use of specific allergens such as grass pollens or $D$. pteronyssius for bronchial challenge tests has been justified on the basis of a relatively poor correlation between skin test and bronchial responsiveness. Whether this adds to the information obtained from a careful history or alters patient management is open to debate.

(3) The assessment of therapy for asthma. Bronchial provocation tests have been extensively used in the evaluation of drugs used in the treatment of asthma. The drugs can be given either to 'treat' an episode of induced bronchoconstriction or given prior to the provocation test to examine the way in which the response may be modified. It is important not to extrapolate automatically from these results to the events which take place during a spontaneous attack of asthma.

(4) To examine the pathogenesis of asthma. A further application of bronchial provocation tests is to examine possible mechanisms contributing to the airway narrowing in patients with asthma. This may involve studying variations in bronchial reactivity which occur either spontaneously or as a result of 'therapeutic intervention'.

Much of the debate as to the value and interpretation of the results of bronchial provocation tests may arise from major differences in methodology. Although an attempt has been made to introduce standard methods (Chai, Farr, Froehlich, Mathison, McLean, Rosenthal, Sheffer, Spector \& Townley, 1975), these have not been universally adopted. It is not possible in this brief review to consider in detail all the variations in technique but factors which merit discussion include the type of challenge and method of administration, the measurement of the response, the interpretation of the result and biological factors which may modify the response. 


\section{The type of bronchial challenge}

A major problem lies in the wide variety of stimuli which may trigger an asthmatic attack and the methods by which they can be delivered. Challenge stimuli have included specific allergens, non-specific pharmacological stimuli such as histamine or methylcholine, irritant stimuli like sulphur dioxide, smoke or cold air and exercise.

\section{Specific allergens}

Exposure to specific allergens is most frequently performed in the laboratory. They are usually given by inhalation although ingestion is the more appropriate route in certain instances, e.g. aspirin sensitivity. For inhalation challenge, serial dilutions of antigenic extract are prepared. A recommended diluent contains $0.5 \%$ sodium chloride, $0.275 \%$ sodium bicarbonate and $0.4 \%$ phenol (Chai et al., 1975). The concentration should be expressed on a weight per volume basis. The initial concentration should produce no significant skin (prick) test response and should be preceded by inhalation of the diluent alone. Serial increases in concentrations are given until a certain pre-determined change in lung function is obtained. When using the delivery system recommended by Chai et al. (1975) suitable incremental increase are $1: 500,000 ; 1: 100,000$; $1: 50,000 ; 1: 10,000 ; 1: 5,000$ and $1: 1000$.

Inhalation challenge with allergens has generally been limited to those patients in whom the clinical history or immunological tests have suggested possible allergic features. Two main patterns of reaction can be elicited: immediate and nonimmediate.

The immediate response occurs rapidly, is maximal at about $10 \mathrm{~min}$ and usually resolves spontaneously over $1-2 \mathrm{~h}$. The pattern of the reaction is analogous to the appearance and duration of a Type 1 skin test reaction which is invariably positive in patients who develop a positive bronchial reaction. The converse is not necessarily true since there are many atopic subjects who have no significant bronchial response and the factors which result in an atopic individual developing asthma have not been satisfactorily determined.

The non-immediate asthmatic reactions occur in only a minority of patients and there are several different patterns. The most common response occurs 5-8 h after the challenge and may be associated with type III immune-complex skin test reactions. It can be controlled by corticosteroids. Other patterns include an earlier reaction at about $2-3 \mathrm{~h}$ and a later reaction usually occurring at night which may recur for several nights in succession without further exposure (Davis, Green \& Schofield, 1976). The precise mechanism of these late reactions is uncertain and their occurrence unpredictable. They represent a potential hazard when performing bronchial challenge test with allergens, and on initial exposure it is wiser to admit the patient to hospital for overnight observation.

\section{Non-specific pharmacological stimuli}

A variety of substances will produce a constrictor response in all subjects if given in sufficient concentration. Histamine and cholinergic derivatives have been used most extensively although bradykinin (Herxheimer \& Stresemann, 1961), SRS-A (Herxheimer \& Stresemann, 1962) and prostaglandin $\mathrm{F}_{2} \alpha$ (Mathe, Hedquist, Holmgren \& Svanborg, 1973) have also been studied. Although given parenterally in the earlier studies, more recently the generally adopted route has been inhalation challenge since this minimizes unwanted systemic effects. Although all forms of bronchial challenge are potentially hazardous, providing serial dilutions are given starting at low concentrations this form of challenge is relatively safe and idiosyncratic or late reactions do not occur.

\section{Non-specific irritant stimuli}

Inhalation of certain irritants such as sulphur dioxide, ozone or cold air may produce significant bronchoconstriction in patients with asthma. This has obvious important environmental implications and bronchial challenge has been used to try and determine 'safe' environmental levels of pollutants. The mechanism of action is probably via a reflex arc initiated by stimulation of irritant receptors in the bronchial mucosa.

\section{Exercise}

The fact that exercise may provoke an attack of asthma was recorded in the seventeenth and eighteenth centuries (Willis, 1679; Floyer, 1717), though its value as a diagnostic aid was emphasized more recently (Jones, Wharton \& Buston, 1963). Although several forms of exercise have been used, that most commonly employed is running either on a treadmill or free range for a period of $6 \mathrm{~min}$. The magnitude of the response is influenced by a number of factors of which the type, severity and duration of exercise are of considerable importance (Anderson, Silverman, König \& Godfrey, 1975). Following an exercise test there is a refractory period of up to $4 \mathrm{~h}$ during which time the response to a subsequent exercise challenge is diminished (Edmunds, Tooley \& Godfrey, 1978). Recent studies have indicated that the ambient temperature and humidity modify the response considerably, the greatest changes being seen when subjects inhale cold dry air (Strauss, McFadden, Ingram, Deal \& Jaeger, 1978; Deal, McFadden, Ingram, Strauss \& Jaeger, 1979). 


\section{$\beta$-adrenoceptor blocking drugs}

The observation that $\beta$-adrenoceptor blocking drugs may provoke an attack of asthma was first made in the mid 1960s (McNeill, 1964). They are rarely given as a diagnostic challenge test and recent studies have attempted to identify those $\beta$-adrenoceptor blockers that have a greater affinity for cardiac rather than bronchial receptors (Decalmer, Chatterjee, Cruickshank, Benson \& Sterling, 1978; McGavin \& Williams, 1978).

\section{The technique of inhalation challenge}

When bronchial challenges are given by inhalation, serial dilutions or suspensions are nebulized to provide a fine mist of droplets. The amount deposited in the bronchial tree is only a small percentage of the output from the nebulizer, and estimates of the dose delivered at the mouth do not necessarily provide an accurate reflection of the amount reaching the airways. The most important factors determining the site of deposition are the particle size, the pattern of breathing and the airway geometry.

\section{Choice of nebulizer}

There are a large number of nebulizers available for use in inhalation challenge. For any individual laboratory the exact choice of nebulizer is probably less important than standardization and control of other factors which determine aerosol deposition. However, comparisons between studies using different nebulizers are difficult to make because of wide variations in particle size and in volume output of fluid per litre of air. Although it is possible to obtain monodisperse aerosols (all particles of a similar size), most of the currently used nebulizers produce particles which range in diameter from $0.5 \mu$ to $20 \mu$. The optimal size for deposition in the tracheobronchial tree is between 1 and $6 \mu$ (Morrow, 1970; Muir, 1972). Larger particles tend to impact on the upper respiratory tract and smaller ones are either deposited in the alveoli or exhaled.

In the United Kingdom the most commonly used nebulizer is that designed by Wright (1958). A jet of air shatters the liquid into separate droplets. The larger droplets are removed by an efficient baffle and the maximum droplet diameter is about $8 \mu$. The total mass concentration is about $30-40 \mathrm{mg}$ fluid/litre of air (Muir, 1972). There are a number of other nebulizers which operate on this principle, all of which produce some droplets of appropriate size for deposition in the bronchi (Mercer, Goddard \& Flores, 1965).

Ultrasonic nebulizers are capable of achieving a very large volume output in excess of $200 \mathrm{mg}$ water/litre of air. This is obtained by producing a dense mist of droplets (1-2 million/cc of air) with mass median diameter of about $6 \mu$. Thus, much larger amounts of fluid are deposited in the tracheobronchial tree per unit ventilation using this type of nebulizer.

The output from these nebulizers may be either continuous or during inspiration only. In the former instance, the aerolized droplets are discharged to atmosphere during expiration, whereas with the latter technique the flow of gas through the nebulizer is breath activated and occurs during inspiration only. Although this makes it easier to determine the dosage, it only reflects the amount delivered at the mouthpiece.

Two further modifications in the administration of an inhalation challenge exist. The first is to use a metering device employing freon as a propellant. This is most commonly used for giving bronchodilators but has also been used for constrictors (Oppenheimer, Rigalto \& Fletcher, 1968). A second modification is that developed by Tiffeneau (1957) and used by Orehek \& Gayrard (1976). The subject inhales from a spirometer bell which acts as a reservoir for droplets produced using one of the conventional nebulizers. This method also provides a record of the pattern of breathing during the inhalation challenge.

\section{The pattern of breathing}

The quantity of inhaled stimulus delivered to any particular site within the bronchial tree is influenced by the pattern of breathing. This includes the total number of breaths, the inspired volume, the inspiratory flow rate and the duration of breathholding. One standard technique is to ask the subject to breathe tidally for a certain time. Although this is a reproducible method within any particular subject, there may be differences between subjects in the pattern of breathing. In order to overcome this problem the aerosol can be inhaled for a certain number of breaths of pre-determined volume. This is possible using the 'reservoir' method or using the 'Dosimeter' developed at the Johns Hopkins hospital (Chai et al., 1975) which is designed to deliver a consistent amount of solution from a DeVilbiss no. 42 nebulizer triggered on inspiration.

\section{Dose-response curves}

Although bronchial reactivity can be assessed by measuring the response to a single challenge (Oppenheimer et al., 1968) there are advantages in constructing a dose-response curve which enables both the threshold dose and the slope of the curve to be determined.

A dose-response curve may be obtained using 
either a non-cumulative or cumulative technique. A non-cumulative method assumes that there is no residual effect from previous administration of the stimulus and can be achieved either by increasing the concentration or by maintaining concentration constant and increasing the duration of the challenge. For most irritant stimuli, e.g. cold air, citric acid, the response occurs almost instantaneously and is over in 1-2 min. Using histamine and methylcholine the maximum response occurs at 1-2 min. The duration of the response usually varies between 5 and $30 \mathrm{~min}$ and is related to the initial magnitude of the response, i.e. the greater the response the longer the duration.

When using a cumulative technique it is assumed that each successive challenge is superimposed on the effects of previous challenges. Since it is unlikely that even longer acting stimuli maintain a constant plateau effect, it is important to have a constant time interval between challenges. Carbacol has a relatively long duration of action and has been used to construct cumulative dose-response curves (Orehek, Gayrard, Smith, Grimaud \& Charpin, 1977).

\section{Methods for measuring the response}

The assessment of bronchial reactivity depends on the ability to measure a change in bronchial calibre following a constrictor stimulus. This is usually done indirectly using tests of pulmonary function which reflect a change within the airways. The most commonly used tests are either those requiring a forced expiration or the measurement of airway resistance. In deciding on the choice of any particular test, certain questions are necessary.

\section{(a) What is the purpose of the test?}

In clinical studies, especially if applied to large populations, a major requirement is that the test should be simple for subject and operator and should not involve the use of complex and expensive equipment. Thus the forced expiratory volume in one second $\left(\mathrm{FEV}_{1}\right)$ which has the advantages of simplicity and reproducibility has been especially popular.

\section{(b) Is the test sensitive?}

Much attention has been paid recently to the development of sensitive tests which enable the detection of minor degrees of airway narrowing. Although some of the newer tests of airway function may appear to show large changes following bronchial challenge, to be significant this change must be greater than the spontaneous variability of the test used. Thus, in considering the sensitivity of a test, its reproducibility must be taken into account. In fact, virtually any test will detect a change if a large enough stimulus is given. The only advantage of a more sensitive test is that it provides a greater margin of safety and reduces the danger of a severe attack of asthma.

(c) Will the test itself influence the degree of bronchoconstriction?

A number of the commonly used tests of airway function involve a forced expiration following inhalation to total lung capacity. In normal subjects a deep inspiration may reduce the change in airway resistance after a constrictor challenge (Nadel \& Tierney, 1961). The radial traction exerted on the bronchi at full inflation is sufficient to overcome the effect of a constrictor stimulus in this situation and there is a time delay before the muscle returns to the fully contracted state.

In patients with asthma the situation is more complex. Maximal inspiration may itself cause bronchoconstriction presumably via a vagal reflex (Simonsson, Jacobs \& Nadel, 1967) and this increase in bronchomotor tone has been shown to potentiate the effect of an inhaled constrictor stimulus (Orehek, Gayrard, Grimaud \& Charpin, 1975b). To overcome this problem maximum expiratory flows have been measured during manoeuvres starting below total lung capacity (the partial expiratory flow volume curve) (Bouhuys, Hurt, Kim \& Zapletal, 1969). The measurement of airway resistance obviates the necessity of a maximal inspiration.

\section{(d) Does the test measure a change in airway calibre?}

When examining possible mechanisms of bronchial hyperreactivity it is important to consider how and to what extent changes in the various tests used may be modified by factors other than a change in airway calibre. The physiological determinants of maximum expiratory flow and airway resistance have been discussed in the preceding papers in this series and will not be considered in detail. However, a constrictor stimulus as well as reducing airway calibre may also change the compliance of both lung and airways. These complex inter-relationships make the interpretation of changes in the forced expiratory volume in one second $\left(\mathrm{FEV}_{1}\right)$ and maximal expiratory flows impossible to analyse simply in terms of a change in airway calibre.

The airway resistance, measured under quasi-static conditions, is more directly related to airway calibre. However, the airway consists of a complex branching network and the changes in airway resistance are mainly determined by alterations in the more central conducting airways. In addition, airway calibre and thus airway resistance depends on the lung volume (TGV) at which it is measured. Following bronchial challenge both and Raw and TGV may increase. 
Correction for a change in volume by using the specific airway conductance is only valid if the conductance-volume relationship is a straight line with its origin at zero volume (Pride, 1971).

Because of the problems of interpreting changes in physiological measurements in terms of changes in airway calibre, direct measurements from bronchograms have been made (Macklem, Fraser \& Bates, 1963 ) and this has been used to examine bronchial reactivity (Benson \& Graf, 1977). This is a time consuming method and its invasive nature makes it unsuitable for routine clinical studies, but it does provide direct evidence of both the degree and site of response in the bronchial tree following bronchial challenge.

\section{The interpretation of results}

The criteria for defining a significant response have varied considerably and depend partly on the nature of the challenge. The simplest method is to use a single challenge and accept that subjects who show a certain arbitrarily defined change in lung function have bronchial hyperreactivity. This approach is exemplified by the standard exercise test. A significant response has varied from the detection of wheezing on auscultation (Irnell \& Swartling, 1966), a fall in peak expiratory flow of $25 \%$ or more (Poppius, Muittari, Kreus, Korhonein \& Viljanen, 1970), or a change in the Jones lability index of between 40 and $65 \%$. This latter method of expressing the results takes into account both the bronchodilation during exercise and the constriction following exercise (Jones, 1966). The limitations of this method are that they rely on arbitrarily selected criteria and assume two distinct populations - 'responders' and 'nonresponders'.

An alternative approach is to construct a doseresponse curve to a constrictor stimulus which may provide greater information about the behaviour of the bronchial tree. Orehek \& Gayrard (1976) have equated the term 'sensitivity' with the threshold dose and 'reactivity' as the gradient of the dose-response curve and have shown that they need not behave in similar fashion (Orehek et al., 1977). Once again there is no general agreement about the method of plotting results since the dose has been represented either on arithmetic or logarithmic scales and the response given as an absolute value or a percentage change from baseline.

The use of percentage change has arisen mainly because of the problem of comparing responsiveness when starting from different baseline function. During laminar flow there is an exponential relationship between radius and resistance (Poiseville equation) and it can be predicted that patients with pre-existing airway narrowing will have a greater absolute increase in airway resistance for any given degree of bronchoconstriction (Benson, 1975). When using percentage change, as is most frequently the case, there is an implicit assumption that for example a fall in FEV $_{1}$ from 1 litre to 0.8 litres represents the same bronchial response as a change from 4 litres to 3.2 litres. In fact, the knowledge of the relationship between structure and function is limited and this type of assumption may be unjustified.

In general, bronchial reactivity has been shown to be greatest in patients with more severe airway narrowing. This has been demonstrated when comparing different subjects (Wells, Walker \& Hickler, 1960; Simonsson, 1965; Parker, Bilbo \& Reed, 1965; Makino, 1966; Itkin, 1967), and also in the same subject when studied under different baseline conditions (Bouhuys, Jonsson, Lichtneckert, Lindell, Lundgren, Lundin \& Ringquist, 1960). There have been exceptions to these generalizations (Rubinfeld \& Pain, 1977) which may in part be accounted for by the method of expressing the results (Orehek \& Gayrard, 1977). One method of attempting to overcome this problem is to make comparisons between individuals who have similar baseline lung function (Benson, 1978).

The problem of a shifting baseline also occurs when examining variations in bronchial reactivity after pre-treatment with drugs. Difficulties which arise in the interpretation of results are illustrated when examining the effect of vagal blockade. Although anticholinergics may 'block' the effect of a variety of provoking factors, implying a vagal reflex mechanism (Simonsson et al., 1967; Yu, Galant \& Gold, 1972), the alteration in the resting state of the muscle may itself modify bronchial reactivity (Benson \& Graf, 1977).

\section{Biological factors affecting bronchial reactivity}

A number of biological factors may determine or modify a subject's response to a constrictor challenge. In addition to differences between different clinical groups of patients, bronchial reactivity may vary within an individual subject.

(a) Differences between clinical populations. Although increased bronchial reactivity to nonspecific challenges has been regarded as a diagnostic feature of asthma (American Thoracic Association, 1962; Muittari, 1968), increased bronchial reactivity has also been demonstrated in patients with hayfever and those with chronic bronchitis (Simonsson, 1965; Townley, Dennis \& Itkin, 1965; Klein \& Salvaggio, 1966; Felarca \& Itkin, 1966; Laitinen, 1974; Townley, Ryo, Kolotkin \& Kang, 1975). In general, patients with asthma are more reactive than chronic bronchitics but there is a 
significant overlap between the groups. Bronchial provocation tests may be of some value in patients who have normal lung function at the time of study (Parker et al., 1965). In patients with airway obstruction, the response to a bronchodilator is safer and likely to be of equal diagnostic value (Benson, 1978).

(b) Variation within an individual. Several studies have shown that in any individual, providing there is no significant change in the clinical state and severity of their airway obstruction, the response to a constrictor stimulus is reproducible (Itkin, 1967; Grimaud, Fondarai, Aldebert \& Charpin, 1967; Spector \& Farr, 1975). However, variations do occur especially in patients with asthma (Graham, Heim \& Constantine, 1967). Factors which result in increased reactivity include a recent exacerbation of asthma (Geubelle, Borlee-Hermans \& Leclercq-Foucart, 1971), a respiratory tract infection (Parker et al., 1965; Empey, Laitinen, Jacobs, Gold \& Nadel, 1977), and exposure to atmospheric pollutants (Orehek, Massari, Gayrard \& Charpin, 1976; Golden, Nadel \& Boushey, 1978). Patients with pollen asthma exhibit increased bronchial reactivity during the summer months (Altounyan, personal communication). There is also a diurnal variation in some patients, reactivity being greatest at night (Vries, Goei, Booij-Noord \& Orie, 1962).

(c) The effect of pre-treatment with pharmacological agents. The effect of pre-treatment with drugs is generally predictable. Bronchodilators such as $\beta$ sympathomimetics, phosphodiesterase inhibitors and anticholinergics all tend to reduce bronchial reactivity. $\beta$-adrenergic receptor antagonists increase reactivity especially in patients with asthma (Zaid \& Beall, 1966; Orehek, Gayrard, Grimaud \& Charpin, 1975a). Corticosteroids do not seem to significantly alter bronchial reactivity except in respect of certain allergic stimuli (Arkins, Schleuter \& Kink, 1968; Spector \& Farr, 1975). In most clinical studies patients are requested to omit using bronchodilators for $24 \mathrm{~h}$ prior to challenge testing. Other forms of treatment are usually continued.

\section{Conclusions}

This review has highlighted some of the problems inherent in bronchial provocation testing. Although recommendations with respect to standardization are helpful (Chai et al., 1975) they also pose certain problems. Simpler methods using a single challenge and relying on tests of forced expiration can be applied to larger populations but there are limitations to their interpretation. More complex studies may be limited to relatively few laboratories. Rather than adopt a rigid format, the type of study should be determined by the question which it is trying to answer. Certain general recommendations can be made.

(1) In the absence of a generally accepted definition of bronchial hyperreactivity, the criteria which have been adopted in any particular study should be clearly stated. In general, information derived from a dose-response curve is of greater value than 'singledose' challenges.

(2) Care should be taken in adopting a protocol which will minimize variations between patients in the quantity of the stimulus administered. This is particularly important for inhalation techniques when the pattern of breathing may vary.

(3) Before studying patients with asthma the range and variability of bronchial reactivity in normal subjects should be established.

(4) In the interests of safety, it is unwise to study patients with severe airway obstruction. Bronchodilators, including aminophylline, sympathomimetics acting on $\beta$-receptors and steroids, should be immediately available. Overnight admission to hospital is advisable for an initial challenge with allergens.

(5) Whilst there are many physiological tests which alter following bronchial provocation, they all have limitations when relating function to structure. The measurement of airway resistance is most closely related to changes in airway size although the magnitude of any change will depend on site as well as degree of airway narrowing. For epidemiological studies tests of forced expiration, e.g. the $\mathrm{FEV}_{1}$ have the advantages of simplicity and reproducibility.

(6) The influence of baseline conditions should be considered when interpreting the results. If possible, comparisons should be made between patients who have similar degrees of airway narrowing.

(7) The events occurring during a bronchial provocation test should not be equated with those taking place during a naturally occurring attack of asthma.

\section{References}

AMERICAN THORACIC SOCIETY (1962). Chronic bronchitis, asthma and pulmonary emphysema. A statement by the Committee on Diagnostic Standards for non-

tuberculous respiratory diseases. Am. Rev. resp. Dis., 85, 762-768.

ANDERSON, S.D., SILVERMAN, M., KONIG, P. \& 
GODFREY, S. (1975). Exercise-induced asthma. Br. J. Dis. Chest., 69, 1-39.

ARKINS, J.A., SCHLEUTER, D.P. \& KINK, J.N. (1968). The effect of corticosteroids on methacholine inhalation in symptomatic bronchial asthma. J. Allergy, 41, 209-216.

BENSON, M.K. (1975). Bronchial hyperreactivity. Br. J. Dis. Chest, 69, 227-239.

BENSON, M.K. (1978). Bronchial responsiveness to inhaled histamine and isoprenaline in patients with airway obstruction. Thorax, 33, 211-213.

BENSON, M.K. \& GRAF, P. (1977). Bronchial reactivity: interaction between vagal stimulation and inhaled histamine. J. appl. Physiol: Respirat. Environ. Exercise Physiol., 43, 643-647.

BOUHUYS, A., HUNT, V.R., KIM, B.M. \& ZAPLETAL, A. (1969). Maximum expiratory flow rates in induced bronchoconstriction in man. J. clin. Invest., 48, 1159-1168.

BOUHUYS, A., JONSSON, R., LICHTNECKERT, S., LINDELL, S.E., LUNDGREN, C., LUNDIN, G. \& RINGQUIST, T.R. (1960). Effects of histamine on pulmonary ventilation in man. Clin. Sci., 19, 79-94.

CHAI, H., FARR, R.S., FROEHLICH, L.A., MATHISON, D.A., McLEAN, J.A., ROSENTHAL, R., SHEFFER, A.L., SPECTOR, S.L. \& TOWNLEY, R.G. (1975). Standardization of bronchial inhalation challenge procedures. J. Allergy clin. Immunol., 56, 323-327.

DAVIS, R.J., GREEN, M. \& SCHOFIELD, N.M. (1976). Recurrent nocturnal asthma after exposure to grain dust. Am. Rev. resp. Dis., 114, 1011-1020.

DEAL, E.C., McFADDEN, E.R., INGRAM, R.H., STRAUSS, R.H. \& JAEGER, J.J. (1979). Role of respiratory heat exchange in production of exercise induced asthma. $J$. appl. Physiol: Respirat. Environ. Exercise Physiol., 46, 467-475.

DECALMER, P.B.S., CHATTERJEE, S.S., CRUICKSHANK, J.M., BENSON, M.K. \& STERLING, G.M. (1978). Beta blockers and asthma. Br. Heart J., 40, 184-189.

EDMUNDS, A.T., TOOLEY, M. \& GODFREY, S. (1978). The refractory period after exercise induced asthma: its duration and relation to severity of exercise. Am. Rev. resp. Dis., 117, 247-254.

EMPEY, D.W., LAITINEN, W.A., JACOBS, L., GOLD, W.M. \& NADEL, J.A. (1976). Mechanisms of bronchial hyperreactivity in normal subjects after respiratory tract infection. Am. Rev. resp. Dis., 113, 131-136.

FELARCA, A.B. \& ITKIN, I.H. (1966). Studies with the quantitive inhalation technique. 1. Curve of dose response to acetyl-beta-methylcholine in patients with asthma of known and unknown origin, hay fever subjects and non-atopic volunteers. J. Allergy, 37, 223-235.

FLOYER, J. (1717). A treatise of the asthma. London: Wilken \& Innes.

GOLDEN, J.A., NADEL, J.A. \& BOUSHEY, H.A. (1978). Bronchial hyperirritability in healthy subjects after exposure to ozone. Am. Rev. resp. Dis., 118, 287-295.

GRAHAM, W.G.B., HEIM, E. \& CONSTANTINE, H.E. (1967). Measurement of airway variation and bronchial reactivity in normal and asthmatic subjects. Am. Rev. resp. Dis., 96, 266-273.

GRIMAUD, C., FONDARAI, J., ALDEBERT, J. \& CHARPIN, J. (1967). Étude de la reproducibilité de test de l'acétylcholine. Poumon et Coeur, 23, 147-153.
GUEBELLE, F., BORLEE-HERMANS, G. \& LECLERQFOUCART, J. (1971). Hyperreactivity of the bronchial tree to histamine in asthmatic children and its variations. Bull. Physiopath. resp., 7, 839-840.

HERXHEIMER, H. \& STRESEMANN, E. (1961). The effect of bradykinin aerosol in guinea pigs and in man. $J$. Physiol. Lond., 158, 38P.

HERXHEIMER, H. \& STRESEMANN, E. (1962). The effect of slow reacting substance (SRS-A) in guinea pigs and asthmatic patients. J. Physiol. Lond., 165, 78P.

IRNELL, L. \& SWARTLING, S. (1966). Maximum expiratory flow rate at rest and during muscular work in patients with bronchial asthma. Scand. J. resp. Dis., 47, 103-108.

ITKIN, I.H. (1967). Bronchial hypersensitivity to mecholyl and histamine in asthmatic subjects. J. Allergy, 40, 244-256.

JONES, R.S. (1966). Assessment of respiratory function in the asthmatic child. Br. med. J., 2, 972-974.

JONES, R.S., WHARTON, M.J. \& BUSTON, M.H. (1963). Place of physical exercise and bronchodilator drugs in the assessment of the asthmatic child. Arch. Dis. Childh., 38, 972-977.

KLEIN, R.C. \& SALVAGGIO, J.E. (1966). Non-specificity of the bronchoconstricting effect of histamine and acetylbeta-methylcholine in patients with obstructive airway disease. J. Allergy, 37, 158-168.

LAITINEN, L.A.I. (1974). Histamine and metacholine challenge testing of bronchial reactivity. Scand. J. resp. Dis., Suppl. 86.

McGAVIN, C.R. \& WILLIAMS, I.P. (1978). The effect of oral propranolol and metoprolol on lung function and exercise performance in chronic airways obstruction. $\mathrm{Br}$. J. dis. Chest, 72, 327-332.

MACKLEM, P.T., FRASER, R.G. \& BATES, D.V. (1963). Bronchial pressures and dimensions in health and obstructive airway disease. J. appl. Physiol., 18, 699-706.

McNEILL, R.S. (1964). Effect of beta-adrenergic blocking agent, propranolol on asthmatics. Lancet, ii, 429-432.

MAKINO, S. (1966). Clinical significance of bronchial sensitivity to acetylcholine and histamine in bronchial asthma. J. Allergy, 38, 127-142.

MATHE, A.A., HEDQUIST, P., HOLMGREN, A. \& SVANBORG, N. (1973). Bronchial hyperreactivity to prostaglandin $F_{2} \alpha$ and histamine in patients with asthma. Br. med. J., 1, 193-196.

MERCER, T.T., GODDARD, R.F. \& FLORES, R.L. (1965). Output characteristics of several commercial nebulisers. Ann. Allergy, 23, 314-320.

MORROW, P.E. (1970). Dynamics of dust removal from the lower airways: measurements and interpretations based upon radioactive aerosols. In Airway Dynamics, eds Bouhuys, A. \& Thomas, C.C., pp. 299-312. Springfield.

MUIR, D.C.F. (1972). Clinical aspects of inhaled particles. Heinemann: London.

MUITTARI, A. (1968). The value of the methacholine test as a diagnostic method in bronchospastic disorders. Ann. Med. intern. Fenn. Fenn, 57, 197-203.

NADEL, J.A. \& TIERNEY, D.F. (1961). Effects of a previous deep inspiration on airway resistance in man. $J$. appl. Physiol., 16, 717-719.

OPPENHEIMER, E.A., RIGATTO, M. \& FLETCHER, C.M. (1968). Airways obstruction before and after isoprenaline, histamine and prednisolone in patients with chronic obstructive bronchitis. Lancet, i, 552-557. 
OREHEK, J. \& GAYRARD, P. (1976). Les tests de provocation bronchique non-spécifiques dans l'asthme. Bull. europ. Physiopath. resp., 12, 565-598.

OREHEK, J. \& GAYRARD, P. (1977). Atropine effects on antigen mediated airway constriction. Am. Rev. resp. Dis., 116, 792-793.

OREHEK, J., GAYRARD, P., GRINAUD, C. \& CHARPIN, J. (1975a). Effect of beta adrenergic blockade on bronchial sensitivity to inhaled acetylcholine in normal subjects. $J$. Allergy clin. Immunol., 55, 164-169.

OREHEK, J., GAYRARD, P., GRINAUD, C. \& CHARPIN, J. (1975b). Effect of maximal expiratory manoeuvres on bronchial sensitivity of asthmatics as compared with normal people. $\mathrm{Br}$. med. J., 1, 123-126.

OREHEK, J., GAYRARD, P., SMITH, A.P., GRINAUD, C. \& CHARPIN, J. (1977). Airway response to Carbachol in normal and asthmatic subjects. Am. Rev. resp. Dis., 115 , 937-943.

OREHEK, J., MASSARI, J.P., GAYRARD, P., GRINAUD, C. \& CHARPIN, J. (1976). Effects of short term, low level nitrogen dioxide exposure on bronchial sensitivity of asthmatic patients. J. clin. Invest., 57, 301-310.

PARKER, C.D., BILBO, R.E. \& REED, C.E. (1965). Metacholine aerosol as test for bronchial asthma. Arch. intern. Med., 115, 453-458.

POPPIUS, H., MUITTARI, A., KREUS, K.E., KORHONEIN, O. \& VILJANEN, A. (1970). Exercise asthma and disodium cromoglycate. $\mathrm{Br}$. med. J., 4, 337-340.

PRIDE, N.B. (1971). Assessment of airflow obstruction. $\mathrm{Br}$. J. Dis. Chest, 65, 135-169.

RUBINFELD, A.R. \& PAIN, M.E.C. (1977). Relationship between bronchial reactivity, airway calibre and severity of asthma. Am. Rev. resp. Dis., 115, 381-388.

SIMONSSON, B.G. (1965). Clinical and physiological studies on chronic bronchitis. III. Bronchial reactivity to inhaled acetylcholine. Acta Allerg., 20, 325-348.

SIMONSSON, B.G., JACOBS, F.M. \& NADEL, J.A. (1967). Role of autonomic nervous system and the cough reflex in the increased responsiveness of airways in patients with obstructive airway disease. J. clin. Invest., 46, 1812-1818.

SPECTOR, S.L. \& FARR, R.S. (1975). A comparison of metacholine and histamine inhalations in asthmatics. $J$. Allergy clin. Immunol., 56, 308-316.

STRAUSS, R.H., McFADDEN, E.R., INGRAM, R.H., DEAL, E.C. \& JAEGER, J.J. (1978). Influence of heat and humidity on the airway obstruction induced by exercise in asthma. $J$. clin. Invest., 61, 433-440.

TIFFENEAU, R. (1957). Examen pulmonaire de l'asthmatique. Déductions diagnostiques, prognostique et thérapeutiques. Masson, Paris 1957, 245P

TOWNLEY, R.G., DENNIS, M.M. \& ITKIN, I.H. (1965). Comparative action of acetyl- $\beta$-methylcholine, histamine and pollen antigens in subjects with hayfever and patients with bronchial asthma. J. Allergy, 36, 121-137.

TOWNLEY, R.G., RYO, U.Y., KOLOTKIN, B.M. \& KANG, B. (1975). Bronchial sensitivity to metacholine in current and former asthmatic and allergic rhinitis patients and control subjects. J. Allergy clin. Immunol., 56, 429-442.

VRIES, K. de., GOEI, J.T., BOOIJ-NOORD, H. \& ORIE, N.G.M. (1962). Changes during $24 \mathrm{~h}$ in the lung function and histamine hyperreactivity of the bronchial tree in asthmatic and bronchitic patients. Int. Arch. Allergy, 20, 93-101.

WELLS, R.E., WALKER, J.E.C. \& HICKLER, R.B. (1960). Effects of cold air on respiratory airflow resistance in patients with respiratory tract disease. New Engl. J. Med., 263, 268-273.

WILlIS, T. (1679). Pharmaceutica Rationales, Part 2. London: Dring, Harper \& Lee.

WRIGHT, B.M. (1958). 'A new nebuliser'. Lancet, ii, 24-25.

YU, D.Y.C., GALANT, S.P. \& GOLD, W.M. (1972). Inhibition of antigen induced bronchoconstriction by atropine in asthmatic patients. J. appl. Physiol., 32, 823-828.

ZAID, G. \& BEALL, G.N. (1966). Bronchial response to $\beta$ adrenergic blockade. New Engl. J. Med., 275, 580-584. 